\title{
The Community Effect and Purkinje Cell Migration in the Cerebellar Cortex: Analysis of Scrambler Chimeric Mice
}

\author{
Huaitao Yang, Patricia Jensen, and Dan Goldowitz \\ Department of Anatomy and Neurobiology, University of Tennessee Health Science Center, Memphis, Tennessee 38163
}

The Disabled-1 protein in mouse is known to be an intercellular signaling component of the Reelin molecular pathway that subserves neuronal migration in several structures in the brain and spinal cord. The scrambler mutant mouse, which is phenotypically identical to the reeler mouse, is due to a mutation in the disabled-1 gene (Howell et al., 1997; Sheldon et al., 1997). The Purkinje cells of the cerebellum express Disabled-1 and experience a massive failure of migration in the scrambler mutant mouse (Howell et al., 1997; Sheldon et al., 1997; Gallagher et al., 1998; Rice et al., 1998). We sought to define the developmental basis of this mutation by studying the Purkinje cell population in experimental mouse aggregation chimeras using a cell marker that permitted the identification of neurons derived from the mutant lineage. We found that a genetically normal component to the environment cannot assist scrambler mutant Purkinje cells in the migratory process. However, the presence of a mutant component to the environment can cause the ectopia of wild-type Purkinje cells. There appears to be a linear relationship between the percentage of the cerebellum that is genetically mutant and the number of wild-type Purkinje cells that express a mutant phenotype. These studies point to the interplay between cell-intrinsic and cell-extrinsic properties in the migration of neurons to form laminated structures during CNS development.

Key words: cerebellum; neuronal migration; mouse chimeras; Disabled-1; Reelin; Purkinje cell
The manner in which populations of cells influence other cells during differentiation, termed the community effect by Gurdon (1988), has been the subject of numerous investigations in developmental biology (Gurdon et al., 1993a,b). The most complex of developing tissues, the mammalian brain, has received only limited attention in this regard, possibly because of the restricted access to important epochs of CNS development. The use of experimental mouse chimeras is one means to explore this issue (Mullen et al., 1997; Rossant and Spence, 1998). By placing cells that are deficient in a given gene in juxtaposition to cells with a normal copy of that gene, it can be determined whether there are influences of mutant or wild-type environments on the developmental processes of cells in situ. Many investigators have used the experimental chimera system to determine the intrinsic or extrinsic nature of unidentified genes in neurological mutant mice. In the near future, when all genes will be known and their function imputed from structure, the intrinsic/extrinsic issue will not be as compelling. However, the chimera situation is also ideal for examining the means by which genetic determinants in cells set the stage, or establish the environment, for subsequent developmental events. It was in this vein that we explored scrambler mouse chimeras to study cell migration in the cerebellum.

The scrambler mutant was identified by its ataxic gait and shown to have a widespread abnormality in cell positioning akin to the phenotype of the reeler mutant mouse (Sweet et al., 1996; Goldowitz et al., 1997; Gonzalez et al., 1997). The scrambler mutation affects the disabled-1 gene that encodes an adaptor

\footnotetext{
Received June 15, 2001; revised Oct. 2, 2001; accepted Oct. 19, 2001.

This research was supported by a University of Tennessee Health Science Center Neuroscience postdoctoral fellowship (H.Y.) and a grant from the Human Frontiers Science Program (D.G.). We thank Richard Cushing for technical assistance.

Correspondence should be addressed to Dan Goldowitz, Department of Anatomy and Neurobiology, University of Tennessee Health Science Center, 855 Monroe Avenue, Memphis, TN 38163. E-mail: dgold@nb.utmem.edu.

Copyright (C) 2002 Society for Neuroscience $0270-6474 / 02 / 220464-07 \$ 15.00 / 0$
}

protein for tyrosine kinase signaling (Sheldon et al., 1997). Disabled-1 is expressed by Reelin-receptive targets and is downstream of Reelin signaling (Rice et al., 1998). During formation of the cerebellar cortex, Disabled-1 expression is restricted to the Purkinje cell population (Rice et al., 1998). In the $\mathrm{scm} / \mathrm{scm}$ mutant, we have determined, as in the reeler cerebellum (Heckroth et al., 1989), that $\sim 95 \%$ of the Purkinje cells fail to migrate to the cerebellar cortex (Goldowitz et al., 1997). The cerebellar Purkinje cells offer an easily quantifiable population to assess the outcome of cell migration. A quantitative assessment of cell phenotype offers the ability to use experimental mouse chimeras to determine whether the scrambler gene acts only in a cellautonomous manner or whether it operates in a more complex manner for its phenotypic expression. In these studies, we found that although genetically mutant Purkinje cells cannot be rescued by a wild-type milieu, genetically normal cells can express a mutant phenotype that is dependent on the percentage of mutant cells in the chimeric cerebellum.

\section{MATERIALS AND METHODS}

Mice and generation of experimental murine chimeras. Scrambler $(\mathrm{C} 3 \mathrm{HeB} /$ $\mathrm{Fe}^{\mathrm{J}} \mathrm{Le}$ ) and $\mathrm{BALB} / \mathrm{c}^{\mathrm{J}}$ mice (originally obtained from the Jackson Laboratory) were born and maintained in our colony at the University of Tennessee Health Science Center animal care facility. Mice were kept on a $14 \mathrm{hr}$ light $/ 10 \mathrm{hr}$ dark cycle with food and water ad libitum. All of the mice were treated in accordance with the Society for Neuroscience policy on the use of animals in research.

Experimental mouse chimeras were generated in a manner that has been described previously (Goldowitz and Mullen, 1982; Goldowitz, 1989; Goldowitz et al., 2000). In brief, four- to eight-cell scrambler $(\mathrm{scm} / \mathrm{scm}$ or $+/ \mathrm{scm})$ and $\mathrm{BALB} / \mathrm{c}^{\mathrm{J}}$ embryos were cultured together overnight. After successful fusion, blastocysts were transplanted into the uterine horn of pseudo-pregnant host ICR females. BALB $/ \mathrm{c}^{\mathrm{J}}$ mice were used as the wild-type component of the chimeras. BALB $/ \mathrm{c}^{\mathrm{J}}$ mice lack the nuclear envelope antigen, Ringo, which is present in neurons of other mice including scrambler (Hamre and Goldowitz, 1997; R. Mullen, personal communication). By using an antibody against Ringo, we were able to distinguish mutant from wild-type cells (see below). 


\begin{tabular}{|c|c|c|c|c|c|}
\hline Animals & Coat color $(\%)$ & cb area ${ }^{a}\left(\mu \mathrm{m}^{2}\right)$ & Total PCs ${ }^{b}$ & E-PCs ${ }^{b}$ & Total GCs ${ }^{c}$ \\
\hline Wild type & 0 & $5,675,733$ & 600 & $0(0.0 \%)$ & 150,266 \\
\hline Chimera 1 & 4 & $4,790,400$ & 471 & $27(5.6 \%)$ & 87,073 \\
\hline Chimera 2 & 8 & $5,451,200$ & 461 & $35(7.5 \%)$ & 90,343 \\
\hline Chimera 3 & 20 & $3,905,600$ & 383 & $58(15.0 \%)$ & 65,762 \\
\hline Chimera 4 & 60 & $3,961,067$ & 502 & $174(34.7 \%)$ & 75,608 \\
\hline Chimera 5 & 98 & $1,974,400$ & 395 & $249(63.1 \%)$ & 24,624 \\
\hline $\mathrm{scm} / \mathrm{scm}$ & 100 & $1,411,200$ & 327 & $310(95.0 \%)$ & 14,168 \\
\hline
\end{tabular}

cb, Cerebella; PCs, Purkinje cells; E-PCs, ectopic Purkinje cells; GCs, granule cells.

${ }^{a}$ Cerebellar areas (cb area) are means of three sections that are at a distance of $150 \mu \mathrm{m}$ from each other in the medial cerebellum.

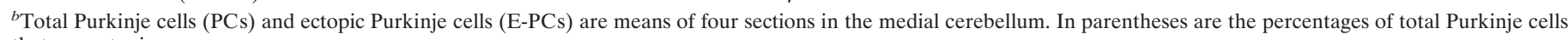
that are ectopic.

${ }^{c}$ Total granule cell numbers are means of two sections at a distance of $150 \mu \mathrm{m}$ from each other in the medial cerebellum.

Tissue preparation. Adult chimeras and control mice $(\mathrm{scm} / \mathrm{scm}$ and $\mathrm{BALB} / \mathrm{c}^{\mathrm{J}}$ ) were deeply anesthetized with Avertin and transcardially perfused with $0.1 \mathrm{M}$ PBS, $\mathrm{pH} 7.2$, followed by paraformaldehyde-lysineperiodate fixative, $\mathrm{pH}$ 6.2, for $20 \mathrm{~min}$ (McLean and Nakane, 1974; Hamre and Goldowitz, 1997). After post-fixation for $4 \mathrm{hr}$ at $4^{\circ} \mathrm{C}$, cerebella were dissected from the skull, rinsed in PBS, and placed overnight in a 5\% sucrose in $0.1 \mathrm{M}$ PB solution. The brains were then dehydrated in a series of ethanols and embedded in wax. Serial, $8 \mu \mathrm{m}$ sagittal sections were mounted on Superfrost Plus slides (Fisher Scientific, Pittsburgh, PA).

Immunohistochemistry for detection of Purkinje cell phenotype and genotype. Slides were dewaxed and rinsed in PBS containing $0.3 \%$ Triton $\mathrm{X}-100$ (PBS/T), blocked with 5\% normal goat serum, and incubated overnight at room temperature with antibodies against either the cerebellar Purkinje cell marker Calbindin [a gift from M. Celio (University of Fribourg, Fribourg, Germany); used at a dilution of 1:1000], Disabled-1 [anti-B3, a gift from Brian Howell (National Institute of Neurological Disorders and Stroke, National Institutes of Health); at a dilution of 1:200), or the non-BALB/ $\mathrm{c}^{\mathrm{J}}$ nuclear antigen marker Ringo [a gift from R. Mullen (Marine Biological Laboratory, Woods Hole, MA); at a dilution of 1:2]. Slides were rinsed with PBS/T and incubated with a biotinylated secondary antibody (1:200) for $30 \mathrm{~min}$ at room temperature. Immunoreactivity was detected using the ABC Elite kit (Vector Laboratories, Burlingame, CA) and diaminobenzidine as the chromagen. For Disabled-1 immunohistochemistry, an additional antigen retrieval protocol was used before incubation with primary antibody (Jiao et al., 1999). Another set of slides was double immunostained for the Ringo (dilution 1:1) and Calbindin (1:200,000) antigens. Finally, a set of antiCalbindin immunostained slides was also counterstained with the nuclear stain cresyl violet.

Quantitative analysis of chimeric tissue. Sections from chimeric and control $\left(\mathrm{scm} / \mathrm{scm}\right.$ and $\left.\mathrm{BALB} / \mathrm{c}^{\mathrm{J}}\right)$ brains were quantified for cerebellar area, total number of granule cells, and total number of Purkinje cells (both ectopic and normally placed). Granule cell and Purkinje cell counts were further subdivided by genotype $\left(\right.$ Ringo $^{-}$or Ringo $^{+}$). To determine cerebellar area, three sections were traced using a camera lucida attachment on a Zeiss microscope $(2.5 \times)$. The areas were traced and calculated in NIH Image, and an average was determined. To estimate the total number of granule cells (as determined by their highly distinct morphology), the area of the internal granule cell layer (IGL) was measured from two nonconsecutive sections in the medial cerebellum using Scion Image software (Beta 3b, based on NIH Image for Macintosh and modified for Windows by Scion Corporation, Frederick, MD). The densities of four $2500 \mu \mathrm{m}^{2}$ regions, located at an equal distance across the IGL, were then calculated and averaged. The total granule cell number was calculated by multiplying the total IGL area by the average density. The same method was applied to determine the numbers of Ringo $^{-}$and Ringo ${ }^{+}$granule cells within the IGL.

Purkinje cell number was determined, using a $25 \times$ objective and the camera lucida, from an average of four evenly spaced sections from the medial cerebellum. Purkinje cells were identified by Calbindin immunopositivity and the presence of a nucleus. The position of each Purkinje cell was assigned to one of three categories: normally placed (in the Purkinje cell layer), ectopic/intermediate (in the IGL or superficial white matter), or ectopic/deep (in the deep cerebellar white matter). In addition, the genotype (Ringo ${ }^{-}$and Ringo ${ }^{+}$) of all Purkinje cells, in each category, was assigned, and totals were calculated.
Determination of Ringo ${ }^{-}$ectopic Purkinje cells in chimeras. To ensure that Purkinje cells counted as Ringo- ${ }^{-}$were not miscounted simply because of the absence of the nucleus, sections were recounted after nuclear staining. Sections double labeled with anti-Calbindin D-28K and anti-Ringo following the protocol above were analyzed and then counterstained with cresyl violet to clearly identify the nuclear envelope or nucleolus of Calbindin/Ringo double-labeled Purkinje cells.

Camera lucida drawings were made to document the position of ectopic $\mathrm{scm} / \mathrm{scm}$ Purkinje cells in Calbindin/Ringo double-stained sections from five $\mathrm{scm} / \mathrm{scm} \leftrightarrow \mathrm{BALB} / \mathrm{c}^{\mathrm{J}}$ chimeras. Coverslips of doublelabeled sections were then removed by immersing slides in xylenes overnight. The slides were hydrated in serial alcohols and stained in $0.03 \%$ cresyl violet solution for $30 \mathrm{~min}$, and coverslips were reapplied. In these counterstained sections, Ringo-negative Purkinje cells in ectopic positions were easily identified and determined to contain or lack a nucleus.

\section{RESULTS}

Experimental mouse chimeras were generated by the aggregation of embryos produced from $\mathrm{scm} / \mathrm{scm}$ female and $+/ \mathrm{scm}$ male matings and embryos produced from $\mathrm{BALB} / \mathrm{c}^{\mathrm{J}}$ female and male matings. An initial measure of chimerism in mice was indicated by the presence of agouti $(+/ \mathrm{scm}$ or $\mathrm{scm} / \mathrm{scm})$ and albino (BALB/ $\mathrm{c}^{\mathrm{J}}$ ) coat colors. The determination of the scrambler genotype $(+/ \mathrm{scm}$ or $\mathrm{scm} / \mathrm{scm})$ was based on the appearance of ectopic Purkinje cells using antibodies against the Purkinje cell marker Calbindin. In the $\mathrm{scm} / \mathrm{scm}$ cerebellum, $95 \%$ of the Purkinje cells are ectopic, whereas in adult wild-type and $+/ \mathrm{scm}$ cerebella there are virtually no ectopic Purkinje cells (Goldowitz et al., 1997). Of the 17 chimeras examined, 9 chimeras had clearly evident populations of ectopic Purkinje cells and were thus identified as genetically $\mathrm{scm} / \mathrm{scm} \leftrightarrow \mathrm{BALB} / \mathrm{c}^{\mathrm{J}}$ chimeras. This proportion of homozygous mutant chimeras is expected from the mating scheme used to produce the scrambler component of chimeras. The percentage of scrambler chimerism of the nine chimeras, based on coat color, ranged from 4 to $99 \%$ agouti (genotypically $\mathrm{scm} /$ $\mathrm{scm}$ ). Five of these nine chimeras were analyzed in detail and are summarized in Table 1. Interestingly, only chimera 9, with the highest percentage of agouti coat color, demonstrated the $\mathrm{scm} /$ scm behavioral phenotype, which included ataxia with truncal swaying and a slightly jerky forward movement during locomotion (Goldowitz et al., 1997).

\section{Qualitative observations of $\mathrm{scm} / \mathrm{scm}$ chimeric cerebella}

There was considerable variation in the gross appearance of the cerebella in the nine chimeras (Fig. $1 C-F$ ). Chimeric cerebella ranged from an almost normal appearance, with only mild differences in the foliation pattern (Fig. $1 C$ ) compared with the wild- 

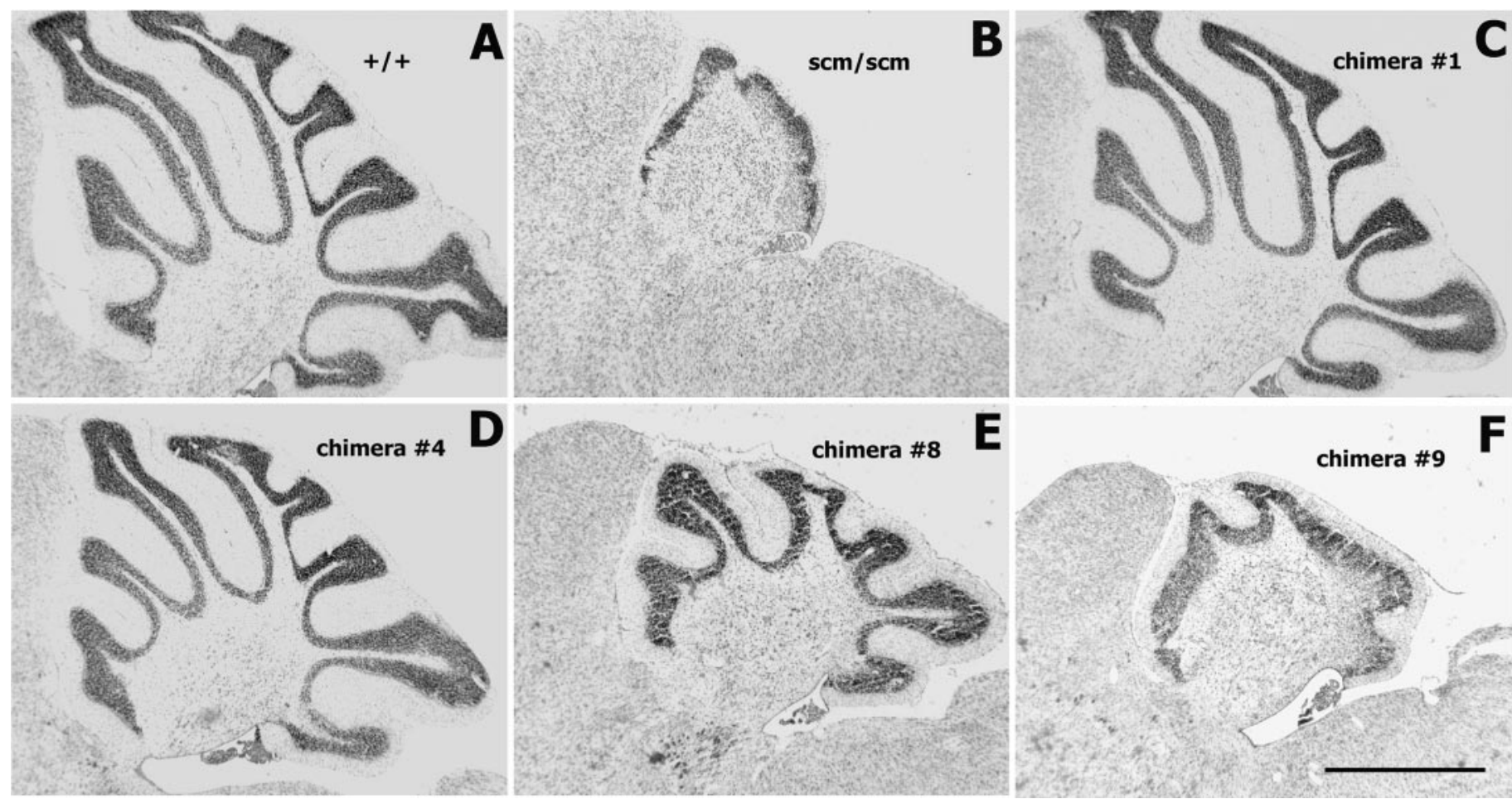

E

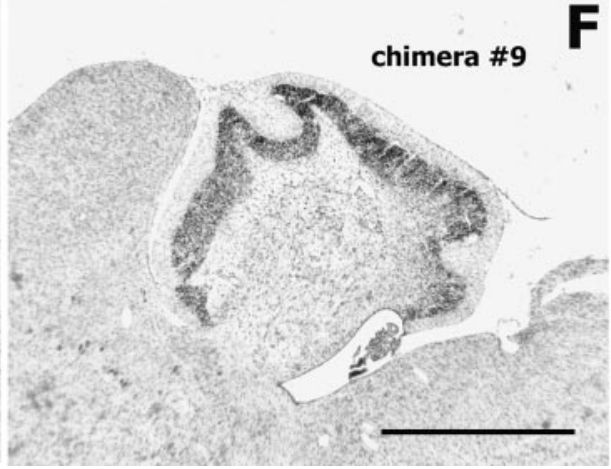

Figure 1. Scrambler chimeric cerebella exhibit a range of phenotypes. Cresyl violet-stained sagittal sections of cerebella from a BALB/c $\mathrm{c}^{\mathrm{J}}$ control $(A)$, a $\mathrm{scm} / \mathrm{scm}$ mouse $(B)$, and four $\mathrm{scm} / \mathrm{scm} \leftrightarrow \mathrm{BALB} / \mathrm{cJ}$ chimeric mice $(C-F)$ are shown. The scrambler cerebellum lacks foliation and is markedly reduced in size. Note that the phenotypes of scrambler chimeric cerebella are intermediate between wild-type and $5 \mathrm{~cm} / \mathrm{scm}$ cerebella. Scale bar (shown in $F$ for $A-F): 500 \mu \mathrm{m}$.

type cerebellum (Fig. 1A), to a cerebellum that was reduced in size, was lacking foliation, and was almost indistinguishable from the $\mathrm{scm} / \mathrm{scm}$ cerebellum (compare chimera 9 in Fig. $1 F$ with the $\mathrm{scm} / \mathrm{scm}$ cerebellum in Fig. $1 B$ ). Along with variations in overall size and foliation, there also appeared to be considerable differences in the populations of granule and Purkinje cells among the chimeras (Fig. 2E-H, Table 1).

In the wild-type cerebellum, Purkinje cells are arranged in a single layer between the molecular layer (ML) and the IGL (Fig. $2 A, C)$. In $\mathrm{scm} / \mathrm{scm}$ mutants, only $5 \%$ of the Purkinje cells are found in this normal position, and the granule cell layer is greatly reduced in size (Goldowitz et al., 1997) (Fig. 2B,D). The other $95 \%$ of Purkinje cells are found in one of two ectopic positions: neighboring nuclear neurons within the deep cerebellar white matter and within or below the IGL (Fig. 2B, arrowheads and arrows, respectively). These same populations of ectopic Purkinje cells were identified in all of the $s \mathrm{~cm} / \mathrm{scm} \leftrightarrow \mathrm{BALB} / \mathrm{c}^{\mathrm{J}}$ chimeras (Fig. 2E-H).

\section{Quantitative observations of $\mathrm{scm} / \mathrm{scm}$ chimeric cerebella}

Areal measurements of $\mathrm{scm} / \mathrm{scm} \leftrightarrow \mathrm{BALB} / \mathrm{c}^{\mathrm{J}}$ cerebella confirmed the variation in cerebellar size (Table 1$)$. The total numbers of cerebellar Purkinje cells in the chimeras were intermediate between wild-type and $\mathrm{scm} / \mathrm{scm}$ cerebella (Table 1). Likewise, the numbers of ectopic Purkinje cells were intermediate between wild-type and $\mathrm{scm} / \mathrm{scm}$ cerebella. Estimates of granule cell number in the medial cerebellum of chimeras were also intermediate between wild-type and mutant cerebella. In general, as the percentage of agouti coat color $(\mathrm{scm} / \mathrm{scm})$ increased in chimeras, the cerebellar size, Purkinje cell number, and granule cell number concomitantly decreased. Conversely, the numbers of ectopic
Purkinje cells increased with increasing percentages of agouti coat color (Table 1).

\section{Genotypic identification of mutant and wild-type cells}

The genotype of granule and Purkinje cells within the chimeric cerebellum was determined using the anti-Ringo antibody. As described in Materials and Methods, the Ringo antibody recognizes a nuclear antigen present in all genetically scrambler neurons (Fig. 3D) and not BALB/c ${ }^{\mathrm{J}}$ neurons (Fig. $3 C$ ). Immunopositive cells have a dark-brown ring outlining the nuclear envelope. In Ringo-immunostained material, granule cells were easily identified by their size and shape, whereas Purkinje cells were identified by double-immunostaining tissue using a highly dilute antiCalbindin antibody solution $(1: 200,000)$ to yield a light-brown cytoplasmic reaction product. All granule and Purkinje cells in the $\mathrm{BALB} / \mathrm{c}^{\mathrm{J}}$ cerebellum were Ringo immunonegative and positioned normally (Fig. $3 \mathrm{C}$ ). In the $\mathrm{scm} / \mathrm{scm}$ cerebellum, all granule and Purkinje cells were Ringo immunopositive (Fig. 3D). Importantly, in the scrambler cerebellum, both ectopic and normally positioned Purkinje cells were Ringo immunopositive.

In all $\mathrm{scm} / \mathrm{scm} \leftrightarrow \mathrm{BALB} / \mathrm{c}^{\mathrm{J}}$ chimeras, the granule cell population was composed of both genetically mutant and wild-type cells (Fig. 3A). As expected, these cells were located in their normal position in the IGL. The percentage of $\mathrm{scm} / \mathrm{scm}$ granule cells in chimeras reflected the general chimerism seen for coat color (Tables 1, 2).

The Purkinje cell population in all chimeras was also composed of both genetically mutant and wild-type cells. Wild-type and mutant Purkinje cells were found in the Purkinje cell layer (Fig. $3 A$ ). However, genetically wild-type cells greatly outnumbered $\mathrm{scm} / \mathrm{scm}$ Purkinje cells within the Purkinje cell layer (Table 2). In each of the $s \mathrm{~cm} / \mathrm{scm} \leftrightarrow \mathrm{BALB} / \mathrm{c}^{\mathrm{J}}$ chimeras, $5-8 \%$ of the $\mathrm{scm} / \mathrm{scm}$ 


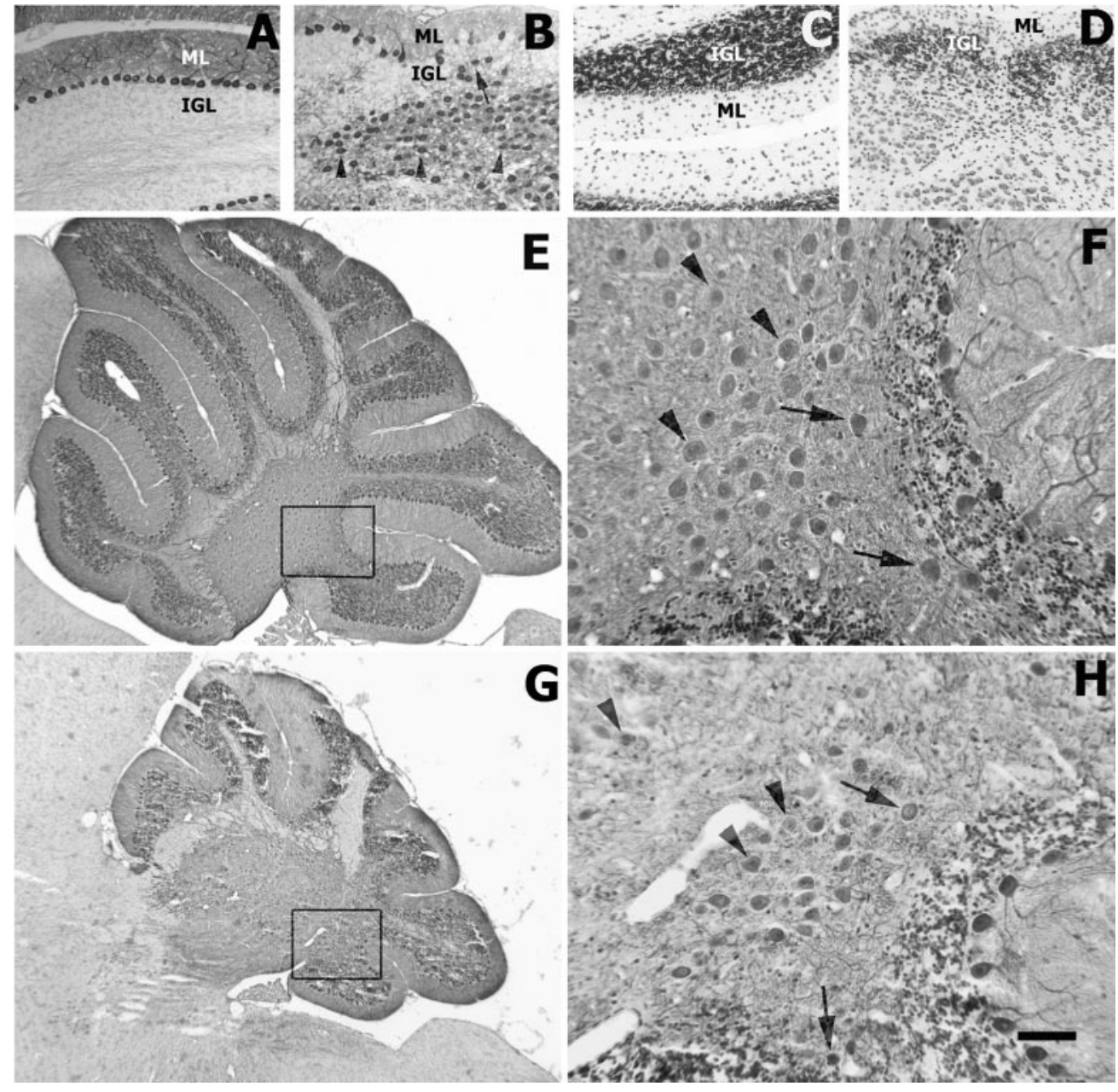

Figure 2. The neuronal phenotypes of the scrambler chimeric cerebellum. $A, B$, The arrangement of Purkinje cells is shown in wild-type $/ \mathrm{BALB} / \mathrm{c}^{\mathrm{J}}$ control $(A)$ and $\mathrm{scm} / \mathrm{scm}(B)$ cerebella stained with Calbindin. In the wild-type cerebellum, Purkinje cells are arranged as a single layer between the molecular layer $(M L)$ and the internal granule cell layer $(I G L)$. In the $\mathrm{scm} / \mathrm{scm}$ cerebellum, most of the Purkinje cells are located in deep (arrowheads) and superficial (arrows) ectopic positions. $C, D$, The abundance and positioning of granule cells are shown in wild-type/BALB/ $/ \mathrm{c}^{\mathrm{J}}$ control $(C)$ and $\mathrm{scm} / \mathrm{scm}(D)$ cerebella stained with cresyl violet. Compared with the wildtype cerebellum, there are fewer granule cells in the IGL than in $\mathrm{scm} / \mathrm{scm}$, although these cells are correctly placed in a discrete IGL. $E-H$, Sagittal sections of two $\mathrm{scm} / \mathrm{scm} \leftrightarrow \mathrm{BALB} / \mathrm{c}^{\mathrm{J}}$ chimeric mice (chimeras 4 and 8) were immunostained with Calbindin and counterstained with cresyl violet. Low-magnification images are shown in $E$ and $G$. The boxed areas are highlighted in $F$ and $H$. Numerous ectopic Purkinje cells are evident, with the majority found deep in the cerebellar cortex (arrowheads) and a smaller percentage of ectopic Purkinje cells located in a more superficial/intermediate position (arrows). Scale bar (shown in $H$ ): $A-D, 200$ $\mu \mathrm{m} ; E, G, 320 \mu \mathrm{m} ; F, H, 100 \mu \mathrm{m}$.
Purkinje cells were normally positioned, a percentage similar to that seen in the scrambler mutant cerebellum (Goldowitz et al., 1997). This percentage of normally placed $\mathrm{scm} / \mathrm{scm}$ Purkinje cells was consistent, notwithstanding the percentage of wild-type Purkinje cells that composed the chimeric cerebellum (Fig. 3E). Thus, the same percentage of mutant Purkinje cells was found in normal positions whether there were $>90 \%$ or $<40 \%$ of wildtype Purkinje cells in the chimeric cerebellum. We found similar results in the analysis of two sections from the lateral cerebellum (data not shown). This finding, that a primarily wild-type environment is unable to rescue the $\mathrm{scm} / \mathrm{scm}$ Purkinje cell ectopia, suggests a cell-autonomous function for the disabled-1 gene.

The genotype of ectopic Purkinje cells was determined in anti-Ringo and anti-Calbindin double-immunostained material. Most of these ectopic Ringo ${ }^{+} \mathrm{scm} / \mathrm{scm}$ cells were found in white matter deep in the cerebellar cortex (Fig. 3B). There was a small number of Ringo ${ }^{+} \mathrm{scm} / \mathrm{scm}$ Purkinje cells found in the more superficial white matter and the IGL (Fig. 3A, Table 2). Most surprisingly, we found Ringo ${ }^{-} \mathrm{BALB} / \mathrm{c}^{\mathrm{J}}$ Purkinje cells in both of these ectopic locations in all chimeras (Fig. 3B, arrowheads). We examined sections from the cerebellar hemispheres and found very similar results (data not shown).

This finding was unexpected, and we felt that it was critical to confirm that the identification of a Purkinje cell as Ringo ${ }^{-} /$wild type in a given section was not because of the absence of the nucleus. As mentioned previously, Ringo labels the nuclear envelope. To confirm the presence of the nucleus in Ringo ${ }^{-}$Pur- kinje cells, sections immunoreacted for Calbindin and Ringo were counterstained with cresyl violet. Ringo ${ }^{-}$Purkinje cells were reconstructed in serial sections using a camera lucida. Both Ringo $^{-}$and Ringo ${ }^{+}$Purkinje cells in ectopic populations were easily identified (Fig. 4A,B). We found that almost all of the Ringo $^{-}$Purkinje cells in ectopic positions were also Ringo ${ }^{-} /$ cresyl violet ${ }^{+}$with clear staining of the nuclear envelope and/or nucleolus (Fig. 4A). Furthermore, when chimeric cerebella were stained with a polyclonal antisera raised to Disabled-1, there were two distinct populations of ectopic Purkinje cells: very lightly stained cells that reflected the small amount of Disabled-1 protein still expressed in the $\mathrm{scm} / \mathrm{scm}$ mutant Purkinje cells (Sheldon et al., 1997) and intensely stained cells that were wild-type Purkinje cells expressing normal levels of Disabled-1 (Fig. 4C,D).

Counts of Ringo ${ }^{-} /$cresyl violet $^{+}$Purkinje cells were made for each chimera. On the basis of these counts, the overall percentages of wild-type, ectopic Purkinje cells were calculated (Table 3). We found that the numbers of ectopically positioned wild-type Purkinje cells increased as the percentage of genotypically $\mathrm{scm} /$ scm Purkinje cells increased (Fig. 5). This finding, that the mutant environment has an affect on wild-type cells, indicates that there is a non-cell-autonomous component of mutant disabled-1 in the positioning of Purkinje cells.

\section{DISCUSSION}

Here we demonstrate that the phenotype of the $\mathrm{scm} / \mathrm{scm}$ chimeric cerebellum is intermediate between wild-type and scrambler 
Figure 3. Genotype of granule and Purkinje cells in $\mathrm{scm} / \mathrm{scm} \leftrightarrow \mathrm{BALB} / \mathrm{c}^{\mathrm{J}}$ chimeric cerebellum. The genotypes of normally positioned and superficially ectopic and deeper ectopic Purkinje cells are illustrated in $A$ and $B$, respectively. Arrows point to mutant cells, and arrowheads point to wild-type cells. There are normally positioned mutant cells in the Purkinje and granule cell layers; however, there is also the presence of apparently genetically wild-type cells in phenotypically mutant positions $(B)$. Control tissue double stained for Calbindin and Ringo is shown $\left(C, \mathrm{BALB} / \mathrm{c}^{\mathrm{J}} ; D, \mathrm{scm} / \mathrm{scm}\right)$ to demonstrate the Ringo cell marking system. Note that no cells are labeled in the $\mathrm{BALB} / \mathrm{c}^{\mathrm{J}}$ cerebellum $(C)$, whereas all cells are labeled in the $\mathrm{scm} / \mathrm{scm}$ cerebellum $(D) . E$, Black bars indicate the percentage of normally placed $\mathrm{scm} / \mathrm{scm}$ Purkinje cells; gray bars mark the overall percentage of $\mathrm{scm} / \mathrm{scm}$ Purkinje cells in five chimeric mice. This graph illustrates that only $5 \%$ of $\mathrm{scm} / \mathrm{scm}$ Purkinje cells are normally placed regardless of the overall $\mathrm{scm} / \mathrm{scm}$ percentage in a chimera. Scale bar (shown in $D$ ): $A, B, 40 \mu \mathrm{m} ; C, D, 50$ $\mu \mathrm{m}$.

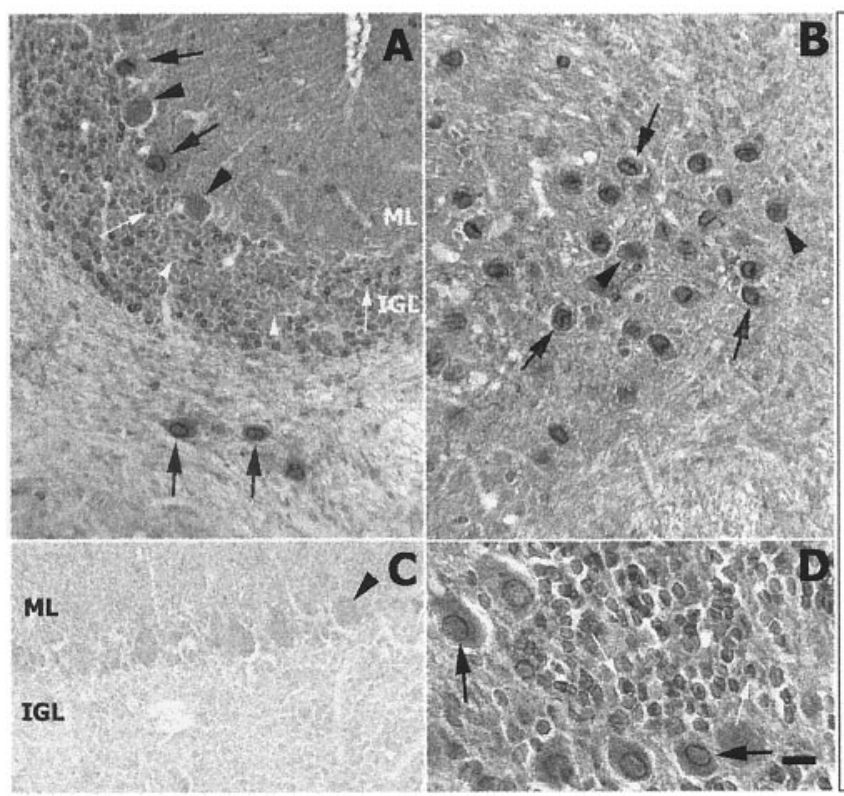

Table 2. Percentage chimerism, normal, and deep ectopic placed $s c m$ Purkinje cells in five $s c m / s c m \leftrightarrow B A L B / c^{J}$ chimeras

\begin{tabular}{|c|c|c|c|c|c|c|c|}
\hline \multirow[b]{2}{*}{ Animals } & \multirow[b]{2}{*}{$\mathrm{Rg}^{+}(\mathrm{scm}) \mathrm{PCs}^{a}$} & \multicolumn{2}{|c|}{$\%$ scm chimerism $^{a}$} & \multicolumn{4}{|c|}{$\%$ scm PCs ${ }^{a}$} \\
\hline & & GCs & PCs & NP & E-total & E-gl-int & E-d \\
\hline Wild type & 0 & $0.0 \%$ & $0.0 \%$ & 0 & 0 & 0 & 0 \\
\hline Chimera 1 & 28 & $1.9 \%$ & $5.8 \%$ & 5.55 & 94.4 & 5.15 & 89.25 \\
\hline Chimera 2 & 37 & $11.7 \%$ & $7.9 \%$ & 8.05 & 91.95 & 20.85 & 71.1 \\
\hline Chimera 3 & 59 & $49.3 \%$ & $15.4 \%$ & 5.09 & 95.0 & 16.95 & 78.0 \\
\hline Chimera 4 & 182 & $39.6 \%$ & $36.2 \%$ & 5.4 & 94.6 & 7.45 & 87.15 \\
\hline Chimera 5 & 258 & $83.6 \%$ & $65.4 \%$ & 5.1 & 96.35 & 29.3 & 67.05 \\
\hline $\mathrm{scm} / \mathrm{scm}$ & 377 & $100 \%$ & $100 \%$ & 5.4 & 94.6 & 14.4 & 80.2 \\
\hline
\end{tabular}

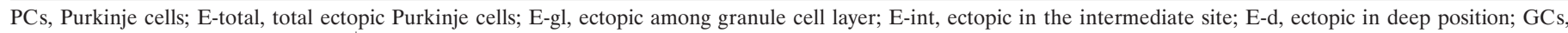
granule cells; $\mathrm{NP}$, normal placed; $\mathrm{Rg}^{+}$, Ringo positive.

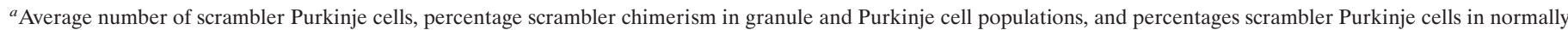

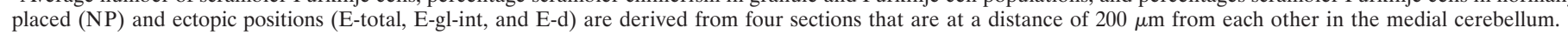

mice. With increasing numbers of $\mathrm{scm} / \mathrm{scm}$ Purkinje cells in a chimera, cerebellar size, foliation, and granule cell number are diminished. Thus, our data indicate that there is a clear relationship between the percentage chimerism of mutant Purkinje cells and the severity of the mutant phenotype. This is in contrast to reeler chimeras in which equal mixtures of mutant and normal cells produced no mutant phenotype in the cerebellum (Terashima et al., 1986). In fact, only when $>90 \%$ reeler cells colonized the chimeric cerebellum was there evidence of a mutant phenotype (Mullen, 1978). This demonstrates the expected cellextrinsic nature of an extracellular matrix-like protein such as Reelin with the intrinsic property expected of a cytoplasmic adaptor molecule such as Disabled-1 (Howell et al., 1997; Sheldon et al., 1997). This cell-intrinsic mechanism is witnessed by the fact that no matter what the contribution of wild-type cells to the chimeric cerebellum, there was a consistent and low level of normally placed mutant Purkinje cells similar to what is seen in the $\mathrm{scm} / \mathrm{scm}$ cerebellum. For example, in chimera 1, the cerebellum of which was almost normal, $\sim 95 \%$ of the mutant Purkinje cells were found in ectopic locations.
What proved to be an unexpected finding was that wild-type Purkinje cells adopted a mutant phenotype when confronted with increasing proportions of mutant Purkinje cells and/or environment. That is, as the number of mutant Purkinje cells increased (also indicative of an elevated presence of mutant cells in the overall chimeric environment), the number of wild-type Purkinje cells found in ectopic positions also increased.

The finding that cellular phenotypes are influenced in one direction but not the other, i.e., genetically mutant Purkinje cells are not aided by the presence of wild-type cells but genetically normal Purkinje cells are hampered in their migration by the presence of mutant cells, appears as an anomaly. This conclusion can be understood by considering that successful migration may be seen as requiring at least two components. First, a cell must have intact signaling pathways and cellular architecture that enable migration. Second, there are environmental conditions that are required for, or that can negatively impact, successful migration (Gao et al., 1992; Jensen et al., 1999). In essence, this is the basis of the community effect applied to a complex system such as the developing brain and can explain our findings that wild-type 


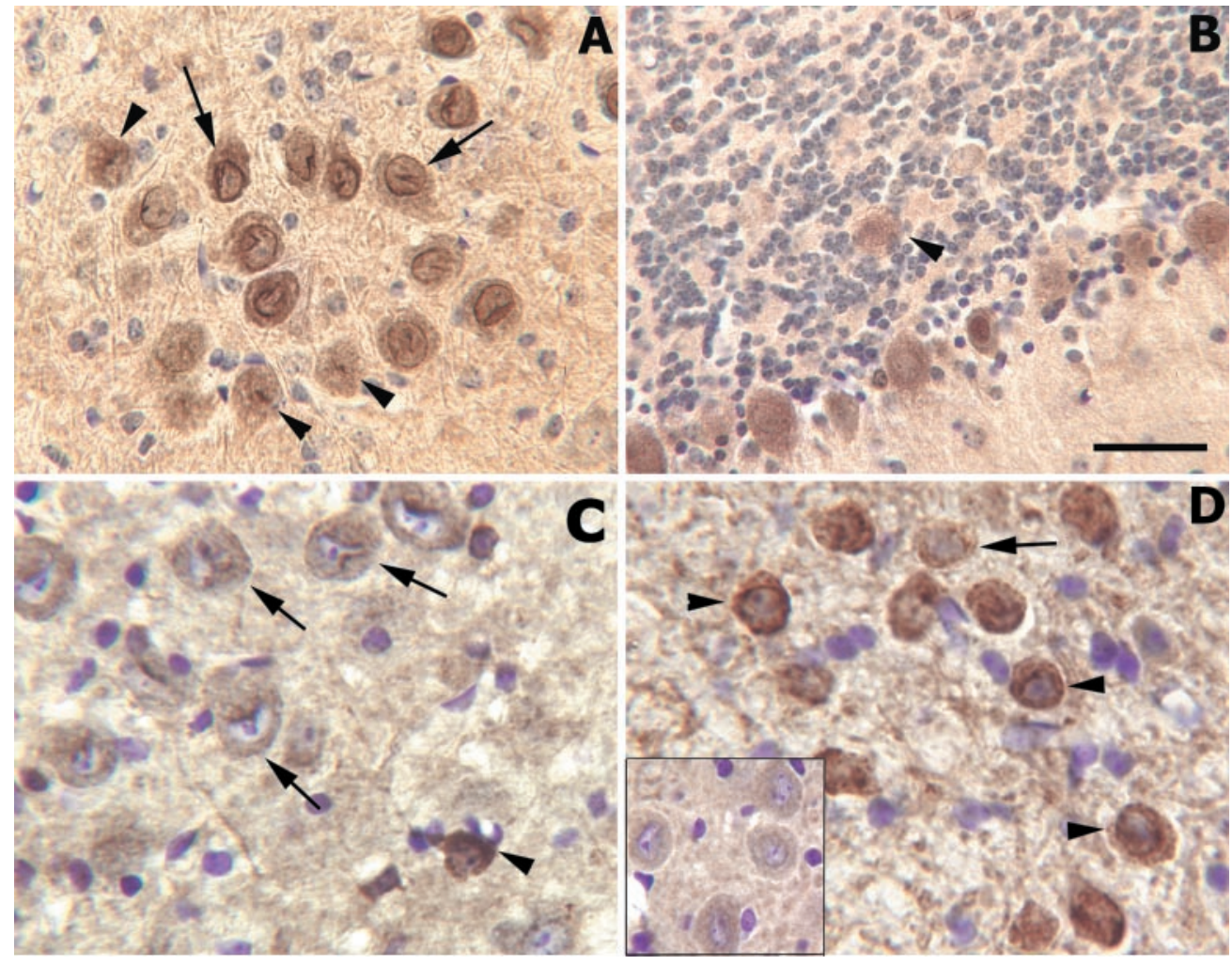

Figure 4. Wild-type Purkinje cells are determined to be phenotypically mutant. $A, B$, Sagittal sections of $\mathrm{scm} /$ $\mathrm{scm} \leftrightarrow \mathrm{BALB} / \mathrm{c}^{\mathrm{J}}$ chimera 2 that have been stained for Calbindin and Ringo immunochemistry and counterstained with cresyl violet. In $A$, wild-type (arrowheads) and $\mathrm{scm} / \mathrm{scm}$ (arrows) Purkinje cells are found to coexist in deep ectopic positions. The cresyl violet stain allows for the easy identification of Purkinje cells by highlighting the nucleus of these cells. In $B$, a wild-type, ectopic Purkinje cell is shown located within the granule cell layer (arrowhead). $C, D, \mathrm{~A}$ low $(C)$ and high $(D)$ percentage scrambler chimeric brain is shown stained with anti-Disabled-1 antibody to confirm the presence of wild-type Purkinje cells (arrowheads) in ectopic positions. Arrows point to weakly immunostained $\mathrm{scm} / \mathrm{scm}$ Purkinje cells. Note in $D$ that the high percentage scrambler chimera has increased numbers of ectopic, wildtype Purkinje cells (arrowheads). The inset in $D$ shows the low level of Disabled-1 immunoreactivity that is present in Purkinje cells in the $\mathrm{scm} / \mathrm{scm}$ cerebellum. Scale bar (shown in $B$ ): $A$, $B, 40 \mu \mathrm{m} ; C, 27 \mu \mathrm{m} ; D, 31 \mu \mathrm{m}$.
Table 3. Ectopic wild-type Purkinje cells in five $s c m / s c m \leftrightarrow B A L B / c^{J}$
chimeras

\begin{tabular}{llcccc} 
& \multirow{2}{*}{$\begin{array}{l}\text { Total wt } \\
\text { Animals }\end{array}$} & \multicolumn{4}{l}{ Ectopic wt PCs PCs $^{a, b}$} \\
\cline { 3 - 6 } & E-gl & E-int & E-d & E-total $^{c}$ \\
\hline Chimera 1 & 441 & 1 & 0 & 6 & $7(1.6 \%)$ \\
Chimera 2 & 423 & 3 & 1 & 2 & $6(1.4 \%)$ \\
Chimera 3 & 323 & 6 & 5 & 10 & $21(6.5 \%)$ \\
Chimera 4 & 315 & 6 & 1 & 29 & $36(11.4 \%)$ \\
Chimera 5 & 130 & 10 & 0 & 20 & $30(23.1 \%)$
\end{tabular}

wt, Wild type; PCs, Purkinje cells; E-gl, ectopic among granule cell layer; E-int, ectopic in the intermediate site; E-d, ectopic in deep position; E-wt, ectopic wild type; E-total, total number of ectopic wild-type Purkinje cells.

${ }^{a}$ Total number of wild-type Purkinje cells are means of four sections that are at a distance of $200 \mu \mathrm{m}$ in the medial cerebellum.

${ }^{b} \mathrm{wt}$, Wild-type Purkinje cells are $\mathrm{Calb}^{+} / \mathrm{Rg}^{-} / \mathrm{CV}^{+}$

${ }^{c}$ The average total number of wild-type Purkinje cells found in ectopic positions. In parentheses is the percentage of total wild-type Purkinje cells that are ectopically placed.

Purkinje cells can express an ectopic phenotype in a mutant environment.

There are at least three environmental conditions that may bring about the ectopia of wild-type Purkinje cells. First, the disabled-1 mutation in scrambler may affect afferent input and impede migration guided by incoming axons. It has been hypothesized that early afferents may provide a migratory substrate for Purkinje cells in the developing cerebellum (Altman and Bayer, 1997), and furthermore it has been shown that these fibers are Disabled-1 positive (Howell et al., 1997; Rice et al., 1998). Second, mutations in the Reelin signaling pathway may hinder the ability of Purkinje cells to detach from radial glia on which they are believed to migrate (Yuasa et al., 1993). There is reasonable evidence to suggest that the mode of action of the Reelin signal-
Percentage of ectopic wildtype (E-wt) and normally placed mutant (NP) Purkinje cells in scm chimeras

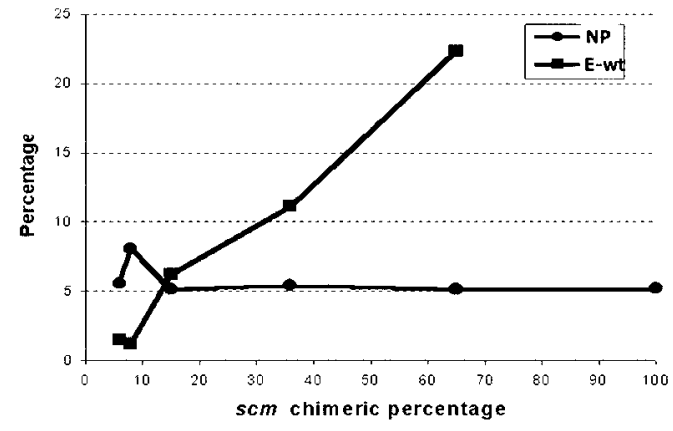

Figure 5. Evidence for non-cell-autonomous action on the placement of wild-type Purkinje cells. Plot of the percentage of $\mathrm{scm} / \mathrm{scm}$ Purkinje cells versus the percentage of ectopic wild-type $(E-w t)$ and the normally placed $(N P) \mathrm{scm} / \mathrm{scm}$ Purkinje cells in five chimeric mice. The bottom line indicates that between 5 and $8 \%$ of the $\mathrm{scm} / \mathrm{scm}$ Purkinje cell population is normally placed regardless of the percentage of wild-type Purkinje cells in the chimeric cerebellum. In contrast, numbers of ectopic wild-type Purkinje cells have a linear relationship with the percentage of $\mathrm{scm} / \mathrm{scm}$ Purkinje cells. Thus, with increasing percentages of $\mathrm{scm} / \mathrm{scm}$ Purkinje cells, more wild-type Purkinje cells are found to express the ectopic phenotype.

ing pathway is to enable migrating cells to leave the radial glial guide (Pinto-Lord et al., 1982). In the scrambler chimeric cerebellum, $\mathrm{scm} / \mathrm{scm}$ Purkinje cells may remain attached to the radial glia and prevent wild-type Purkinje cells from proceeding further. However, we found wild-type ectopic Purkinje cells that do not have neighboring mutant Purkinje cells. This suggests an influence of a possible "group effect" that operates at some distance from the affected cell. Thus, a third possibility is that a defect in signaling from mutant Purkinje cells to the radial glia (or 
some other cell type) may disrupt important instructive events for successful migration.

Our finding of a non-cell-autonomous component in Purkinje cell migration demonstrates the complexity of this signaling pathway. It is only through careful quantitative analysis that the non-cell-autonomous role of Disabled has come to light. This finding highlights the power of the cerebellum as a model system to examine the function of Disabled-1 and other molecules involved in cell migration. Over the past few years, most of the studies designed to explore the function of these molecules have focused on the cortex. However, because of the large number of cell types and overall complexity of the cortex, phenotypic analysis is restricted to qualitative observations. For example, the recent work by Hammond et al. (2001), who analyzed the cortex from blastocyst injection chimeras of disabled-1 null mice, found that wild-type cells could traverse mutant territory to establish an apparently normal "super cortex." This finding is qualitatively similar to our analysis of wild-type Purkinje cells and dramatically illustrates the cell-autonomous nature of the scrambler mutation, but as we found for Purkinje cells, Hammond and colleagues (2001) also found some wild-type cells in ectopic positions. However, the quantitative relationship between chimerism and wild-type cells expressing a mutant phenotype in the chimeric cortex is not easily ascertainable. Such a quantitative relationship as shown in Figure 5 can provide critical insights into cellular interactions in neural development.

Finally, it appears that what we found in cerebellum and Hammond et al. (2001) reported in cortex can be generalized to other regions affected by mutations in the disabled-1 gene. Preliminary examination of the hippocampus in our scrambler chimeras revealed a clear segregation of genotypically mutant and normal cells (our unpublished observations). As we found for the cerebellum, wild-type cells in the hippocampus are segregated in the normal pyramidal cell layer, whereas mutant cells occupy a ragged bilayer that is typical of the scrambler condition. Importantly, in chimeras with increased percentages of mutant cells, we began to find wild-type cells in ectopic positions.

Thus the cellular simplicity of the cerebellum offers a model system in which one can quantify the effects of single molecular differences on cell behaviors such as migration. The chimeric cerebellum is an ideal assay system for the sensitive quantitation of migratory behavior in the brain and demonstrates in the present study that Disabled-1 works in both a cell-intrinsic and cell-extrinsic manner to guide Purkinje cell migration.

\section{REFERENCES}

Altman J, Bayer SA (1997) The ascent and settling of Purkinje cells in relation to their time and site of origin. In: Development of the cerebellar system. In relation to its evolution, structure, and functions (Altman J, Bayer SA, eds), pp 207-229. Boca Raton, FL: CRC.

Gallagher E, Howell BW, Soriano P, Cooper JA, Hawkes R (1998) Cerebellar abnormalities in the disabled (mdab-1) mouse. J Comp Neurol 402:238-251.

Gao WQ, Liu XL, Hatten ME (1992) The weaver gene encodes a nonautonomous signal for CNS neuronal differentiation. Cell 68:841-854.
Goldowitz D (1989) Cell allocation in mammalian CNS formation: evidence from murine interspecies aggregation chimeras. Neuron 3:705-713.

Goldowitz D, Mullen RJ (1982) Granule cell as a site of gene action in the weaver mouse cerebellum: evidence from heterozygous mutant chimeras. J Neurosci 2:1474-1485.

Goldowitz D, Cushing RC, Laywell E, D'Arcangelo G, Sheldon M, Sweet HO, Davisson M, Steindler D, Curran T (1997) Cerebellar disorganization characteristic of reeler in scrambler mutant mice despite presence of Reelin. J Neurosci 17:8767-8777.

Goldowitz D, Hamre KM, Przyborski SA, Ackerman SL (2000) Granule cells and cerebellar boundaries: analysis of Unc5h3 mutant chimeras. J Neurosci 20:4129-4137.

Gonzalez JL, Russo CJ, Goldowitz D, Sweet HO, Davisson MT, Walsh CA (1997) Birthdate and cell marker analysis of scrambler: a novel mutation affecting cortical development with a reeler-like phenotype. J Neurosci 17:9204-9211.

Gurdon JB (1988) A community effect in animal development. Nature 336:772-774

Gurdon JB, Kato K, Lemaire P (1993a) The community effect, dorsalization and mesoderm induction. Curr Opin Genet Dev 3:662-667.

Gurdon JB, Lemaire P, Kato K (1993b) Community effects and related phenomena in development. Cell 75:831-834.

Hammond V, Howell B, Godinho L, Tan S-S (2001) Disabled-1 functions cell-autonomously during radial migration, cortical layering of pyramidal neurons. J Neurosci 21:8798-8808.

Hamre KM, Goldowitz D (1997) Meander tail acts intrinsic to granule cell precursors to disrupt cerebellar development: analysis of meander tail chimeric mice. Development 124:4201-4212.

Heckroth JA, Goldowitz D, Eisenman LM (1989) Purkinje cell reduction in the reeler mutant mouse: a quantitative immunohistochemical study. J Comp Neurol 279:546-555.

Howell BW, Hawkes R, Soriano P, Cooper JA (1997) Neuronal position in the developing brain is regulated by mouse disabled-1. Nature 389:733-737.

Jensen P, Surmeier DJ, Goldowitz D (1999) Rescue of cerebellar granule cells from death in weaver NR1 double mutants. J Neurosci 19:7991-7998.

Jiao Y, Sun Z, Lee T, Fusco FR, Kimble TD, Meade CA, Cuthbertson S, Reiner A (1999) A simple and sensitive antigen retrieval method for free-floating and slide-mounted tissue sections. J Neurosci Methods 93:149-162

McLean IW, Nakane PK (1974) Periodate-lysine-paraformaldehyde fixative. A new fixation for immunoelectron microscopy. J Histochem Cytochem 22:1077-1083.

Mullen RJ (1977) Genetic dissection of the CNS with mutant-normal mouse and rat chimeras. In: Society for Neuroscience symposium (Cowan WM, Ferrendelli JA, eds), pp 47-65. Bethesda, MD: Society for Neuroscience.

Mullen RJ, Hamre KM, Goldowitz D (1997) Cerebellar mutant mice and chimeras revisited. Perspect Dev Neurobiol 5:43-55.

Pinto-Lord MC, Evrard P, Caviness Jr VS (1982) Obstructed neuronal migration along radial glial fibers in the neocortex of the reeler mouse: a Golgi-EM analysis. Brain Res 256:379-393.

Rice DS, Sheldon M, D'Arcangelo G, Nakajima K, Goldowitz D, Curran T (1998) Disabled-1 acts downstream of Reelin in a signaling pathway that controls laminar organization in the mammalian brain. Development 125:3719-3729.

Rossant J, Spence A (1998) Chimeras and mosaics in mouse mutant analysis. Trends Genet 14:358-363.

Sheldon M, Rice DS, D'Arcangelo G, Yoneshima H, Nakajima K, Mikoshiba K, Howell BW, Cooper JA, Goldowitz D, Curran T (1997) Scrambler and yotari disrupt the disabled gene and produce a reelerlike phenotype in mice. Nature 389:730-733.

Sweet HO, Bronson RT, Johnson KR, Cook SA, Davisson MT (1996) Scrambler, a new neurological mutation of the mouse with abnormalities of neuronal migration. Mamm Genome 7:798-802.

Terashima T, Inoue K, Inoue Y, Yokoyama M, Mikoshiba K (1986) Observations on the cerebellum of normal-reeler mutant mouse chimera. J Comp Neurol 252:264-278.

Yuasa S, Kitoh J, Oda S, Kawamura K (1993) Obstructed migration of Purkinje cells in the developing cerebellum of the reeler mutant mouse. Anat Embryol (Berl) 188:317-329. 